\title{
Effects of Hypericum scabrum extract on dentate gyrus synaptic plasticity in high fat diet-fed rats
}

\author{
Ghazaleh Omidi ${ }^{1 \dagger}$, Arezoo Rezvani-Kamran ${ }^{1 \dagger}$, Ahmad Ganji1, Somayeh Komaki, Farshid Etaee ${ }^{1,2}$, \\ Masoumeh Asadbegi $i^{1}$ and Alireza Komaki ${ }^{1,3^{*}}$ (D)
}

\begin{abstract}
High-fat diet (HFD) can induce deficits in neural function, oxidative stress, and decrease hippocampal neurogenesis. Hypericum (H.) scabrum extract (Ext) contains compounds that could treat neurological disorders. This study aimed to examine the neuroprotective impacts of the H. scabrum Ext on hippocampal synaptic plasticity in rats that were fed HFD. Fifty-four male Wistar rats (220 $\pm 10 \mathrm{~g}$ ) were randomly arranged in six groups: (1) HFD group; (2) HFD + Ext300 group; (3) HFD + Ext100 group; (4) Control group; (5) Ext 300 mg/kg group; (6) Ext 100 mg/kg group. These protocols were administrated for 3 months. After this stage, a stimulating electrode was implanted in the perforant pathway (PP), and a bipolar recording electrode was embedded into the dentate gyrus (DG). Long-term potentiation (LTP) was provoked by high-frequency stimulation (HFS) of the PP. Field excitatory postsynaptic potentials (EPSP) and population spikes (PS) were recorded at 5, 30, and 60 min after HFS. The HFD group exhibited a large and significant decrease in their PS amplitude and EPSP slope as compared to the control and extract groups. In reverse, H. scabrum administration in the HFD + Ext rats reversed the effect of HFD on the PS amplitude and EPSP slope. The results of the study support that H. scabrum Ext can inhibit diminished synaptic plasticity caused by the HFD. These effects are probably due to the extreme antioxidant impacts of the Ext and its capability to scavenge free radicals.
\end{abstract}

Keywords: Synaptic plasticity, Hypericum scabrum, High-fat diet, Long-term potentiation antioxidant

\section{Introduction}

Modifications in diet and lifestyle, which may have happened with industrialization, urbanization, economic development, and market globalization have occurred previously [1]. It is assumed that lifestyle plays an essential role in maintaining neural function [2]. The continuous and long-term consumption of a high-fat diet (HFD) leads to weight gain and obesity [3]. HFD is the most significant risk factor for diseases related to lifestyle [4].

\footnotetext{
*Correspondence: alirezakomaki@gmail.com; Komaki@umsha.ac.ir ${ }^{\dagger}$ Ghazaleh Omidi and Arezoo Rezvani-Kamran contributed equally to this work

${ }^{1}$ Neurophysiology Research Center, Hamadan University of Medical Sciences, Hamadan, Iran

Full list of author information is available at the end of the article
}

The increased incidence of obesity and obesity-associated comorbidities is a global health concern [4]. Although the adverse effects of obesity in the brain are unclear, studies have suggested that obesity and body fat deposition play an essential role in the pathogenesis of certain brain-related disorders $[3,5,6]$. Recent studies have also demonstrated that HFD consumption and obesity are correlated with cognitive damage and a raised chance of expanding dementia $[7,8]$.

In addition, recent data suggest that acute consumption of HFD can lead to memory deficits and significant brain inflammation [9]. Obesity is also linked to apparent oxidative stress and chronic inflammatory status. Oxidative stress along with a decline in antioxidant defenses cause

(c) The Author(s) 2020. This article is licensed under a Creative Commons Attribution 4.0 International License, which permits use, sharing, adaptation, distribution and reproduction in any medium or format, as long as you give appropriate credit to the original author(s) and the source, provide a link to the Creative Commons licence, and indicate if changes were made. The images or other third party material in this article are included in the article's Creative Commons licence, unless indicated otherwise in a credit line to the material. If material is not included in the article's Creative Commons licence and your intended use is not permitted by statutory regulation or exceeds the permitted use, you will need to obtain permission directly from the copyright holder. To view a copy of this licence, visit http://creativecommons.org/licenses/by/4.0/. 
irreversible damage to macromolecules [10] and disruption in redox signaling mechanisms $[11,12]$.

An HFD reduces molecules related to learning and memory, such as levels of brain-derived neurotrophic factor (BDNF), and dopamine (DA) [13]. In animal studies, HFD has been shown to impair hippocampal neurogenesis and specifically, synaptic plasticity in the dentate gyrus [14-16]. HFD can decrease hippocampal neurogenesis and lead to oxidative stress by provoking lipid peroxidation in the hippocampus [16]. Therefore, it has been reported that an HFD causes cellular injury by inducing oxidative stress $[17,18]$. Additionally, HFD elevates the levels of neuroinflammation markers in the brain [19] and it might cause degenerative disorders via insulin resistance $[20,21]$.

The reactive oxygen species (ROS) have an impact on various physiological activities. Nevertheless, when ROS concentration exceeds the antioxidative capability of an organism, it causes oxidative damage to cellular elements [22]. Previous studies have shown the role of oxidative damage in memory deficits in rats and humans [23]. The brain is susceptible to oxidative stress because of its high amount of polyunsaturated fatty acids (lipid peroxidation), high oxygen utilization, low levels of antioxidant protection, and the presence of redox-active metals (Fe, $\mathrm{Cu}$ [ [24]. Previous studies have emphasized the importance of antioxidant treatment in the prevention of oxidative stress-induced neuronal injury [25].

Herbs possess some of the most potent natural antioxidants such as phenols, phenolic elements, or flavonoids [26]. Recent studies have indicated promising effects of herbal medicines in the treatment of various memory disorders [27-29]. These effects could correlate to their antioxidant and anti-inflammatory properties [30-32].

Hypericum (Hypericaceae) (H.) genus includes over 400 species and is distributed all over the world. It is welldistributed over subtropical regions and tropical, as well as across Africa, Asia, Europe, and North America [33, 34]. The therapeutic effect of Hypericum (H.) species is related to the presence of various bioactive compounds, including flavonoids, phloroglucinols, naphthodianthrones, phenolic acids and also essential oil [35, 36]. Hypericum (H.) scabrum extract (Ext) contains flavonoids such as quercitrin and quercetin that exhibit free radical scavenging action. The antioxidant activity of quercetin was confirmed by the inhibition of lipid peroxidation [37]. Clinical effects of Hypericum include amelioration of neurological disorders, anti-anxiety, antidepressant, antioxidant, anti-inflammatory, anticonvulsant, antiviral, antifungal, and wound healing $[34,35,38,39]$. $\mathrm{H}$. scabrum essential oil may be helpful in treating the central nervous system disorders [35].
Long-term potentiation (LTP) is a kind of synaptic plasticity, which is established as a long-lasting augmentation of synaptic communications [40]. This phenomenon in the hippocampus and elsewhere is a probable synaptic substrate of the long-term learning and memory modifications [41]. The dentate gyrus (DG) is part of the hippocampus which is thought to contribute to process of learning and memory through activity of dentate granule neurons [42]. This part is one of the few areas of the rat brain which continues to produce new neurons well after birth $[43,44]$. In the DG, electrical stimuli delivered to perforant pathway (PP) evoke field excitatory postsynaptic potential (EPSP) $[45,46]$. Hence, we hypothesized that the application of $H$. scabrum Ext would ameliorate HFD-induced synaptic plasticity impairment due to its antioxidant and anti-obesity impacts. In this investigation, we assessed the impacts of $H$. scabrum Ext on LTP impairment induced by HFD.

\section{Methods \\ Animals}

The researchers purchased adult male Wistar rats from Pasteur Institute. All animals were accommodated in a place maintained at a steady temperature $\left(22 \pm 2{ }^{\circ} \mathrm{C}\right)$, $60 \pm 5 \%$ humidity and a 12 -h light-12-h dark cycle. Rats were provided unrestricted access to water and rodent chow. Rats were acclimatized to regular rodent food for 1 week. Fifty-four rats (weighing $220 \pm 10 \mathrm{~g}$ ) were divided into 6 groups $(n=9)$ : (1) HFD group, given an HFD with $45 \%$ energy from fat; (2) HFD + Ext300 group, given an HFD supplemented with $H$. scabrum extract $(300 \mathrm{mg} /$ $\mathrm{kg}$ ); (3) HFD + Ext100 group, given an HFD supplemented with $H$. scabrum extract $(100 \mathrm{mg} / \mathrm{kg})$; (4) control group, given a normal diet with $10 \%$ energy from fat and received the saline through oral gavage once a day for 3 months; (5) H. scabrum $300 \mathrm{mg} / \mathrm{kg}$ (Ext300) group, given the standard diet supplemented with $H$. scabrum (300 mg/kg); (6) H. scabrum $100 \mathrm{mg} / \mathrm{kg}$ (Ext100) group, given the standard diet supplemented with $H$. scabrum $(100 \mathrm{mg} / \mathrm{kg})$. Rats received the extract through oral gavage once a day for 3 months [3, 14, 27]. The gavage was performed from 9:00 to 11:00 a.m. All experimental procedures were done under international standards of animal care approved by the Society for Neuroscience. The experimental timeline is shown in Fig. 1.

\section{Hypericum scabrum extract}

The plant was extracted with $70 \%$ ethanol; then evaporated. The evaporation process included the total removal of ethanol and water [47]. H. scabrum extract at doses of 100 and $300 \mathrm{mg} / \mathrm{kg}$ was given by gavage in the 2 groups that were taking normal diet and in the 2 groups that 


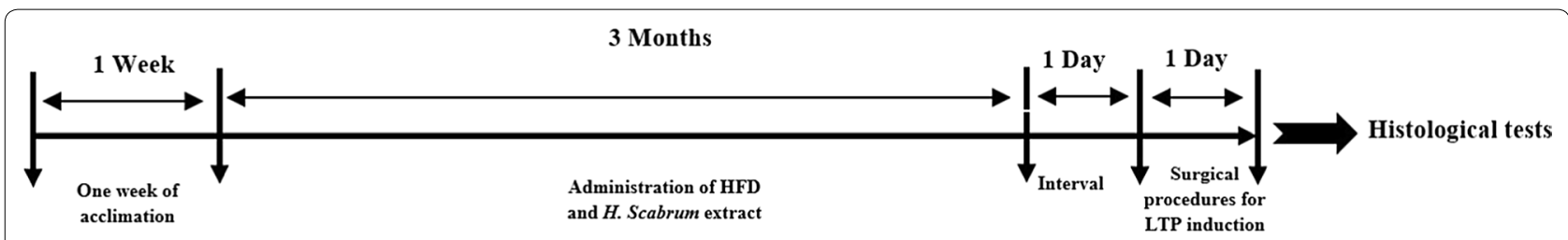

Fig. 1 Experimental timeline. Following 3 months of high-fat diet (HFD) and administration of H. Scabrum extract in the experimental groups, with an intraperitoneal urethane rats were anesthetized and then put in a stereotaxic apparatus for surgery and electrophysiological recording. At least 20 min of stable baseline response was taken and then, using a high-frequency stimulation protocol, long-term potentiation (LTP) was recorded

were taking HFD daily for 3 months. These doses were determined based on former studies [3, 27].

\section{Surgical procedures for LTP induction}

The methodology used in this section was similar to previous studies published by our laboratory $[48,49]$. Under the anesthesia induced by intraperitoneal injection $(1.5 \mathrm{~g} /$ $\mathrm{kg}$ ) of urethane, rats' heads were fixed in a stereotaxic apparatus for surgery and recording. The rats' temperature were maintained at $37.0 \pm 0.2{ }^{\circ} \mathrm{C}$ with an electrical warming pad during the operation. A bipolar stimulating wire electrode, made of stainless-steel with Teflon cover $(125 \mu \mathrm{m}$ inner diameter $/ 175 \mu \mathrm{m}$ external diameter, Advent Co., UK), was inserted into the PP (3.2 $\mathrm{mm}$ ventral below the surface of the skull, $4.3 \mathrm{~mm}$ lateral to the midline, $8.1 \mathrm{~mm}$ posterior to bregma), in accordance with the atlas of Paxinos and Watson [50]. Moreover, a bipolar recording electrode $(2.3 \mathrm{~mm}$ lateral to the midline, $3.8 \mathrm{~mm}$ posterior to bregma) was lowered into the DG until the maximal field EPSP were recorded (2.7-3.2 $\mathrm{mm}$ ventral). The optimal ventral location was obtained by electrophysiological monitoring of the result provoked in the DG following PP stimulation [51, 52].

\section{High-frequency stimulation for LTP induction}

Input/output ( $\mathrm{I} / \mathrm{O})$ response curve was created via different intensities of the single pulse stimulation $(0.1 \mathrm{~ms}$ biphasic square wave pulses at a frequency of $0.1 \mathrm{~Hz}$ ] [49, 52]. Afterward, single stimuli was utilized every $10 \mathrm{~s}$ for at least $30 \mathrm{~min}$, and results were monitored. LTP was provoked by using a $400 \mathrm{~Hz}$ (10 bursts of 20 stimuli, $0.2 \mathrm{~ms}$ stimulus duration (biphasic square wave pulses), $10 \mathrm{~s}$ inter-burst interval) high-frequency stimulation (HFS) protocol at a stimulus intensity that elicited a population spike (PS) amplitude and the field EPSP slope of nearly $50 \%$ of the maximal response. After HFS, EPSP and PS were registered at 5, 30, and $60 \mathrm{~min}$ for assigned alterations into the synaptic response of the DG neurons. For every time point, ten sequential provoked results were averaged at $10 \mathrm{~s}$ stimulus intervals [53, 54]. The single pulses of the post-LTP burst were the same type as those for the I/O curve. A single LTP test was conducted per animal.

\section{Histology}

Following the fulfillment of the investigation, the electrode sites in the hippocampus were defined histologically. After the conclusion of the experiments, rats were completely anesthetized with urethane, and formal-saline was infused via the heart [55]. Coronal brain sections were cut at $50 \mu \mathrm{m}$ and stained with hematoxylin-eosin for histological corroboration and confirmation of electrode tip location [51] (Fig. 2).

\section{Statistical analysis}

We used the GraphPad Prism version 5.00 (GraphPad Software, San Diego, California USA) for data analysis. The data are demonstrated as the mean \pm standard error of the mean (SEM). Two-way repeated measures analysis of variance tests was applied to statistically analyze the results. The Tukey test was used for post hoc comparisons between experimental groups. Statistical differences were considered significant at $P<0.05$.

\section{Results}

Measurement of evoked responses

The DG responses including, EPSP and PS were recorded after stimulation of the PP (Fig. 3). Changes in EPSP slope and PS amplitude were recorded throughout the electrophysiological recording. The amplitude of the PS was determined from the peak of the first positive deflection of the evoked potential to the peak of the next negative potential. Using an input/output curve stimulation intensity was adapted to provoke potentials, including $40 \%$ of the maximal PS amplitude. Then, using a data analysis software, slopes for EPSPs and PS amplitude were calculated.

\section{Effects of $H$. scabrum extract supplementation on the EPSP} slopes of granular cells in the DG of rats fed with HFD

Field potential recordings were obtained in the granular cells in the DG following stimulation of the PP. HFS of the PP caused LTP in the DG. The effects of $H$. 

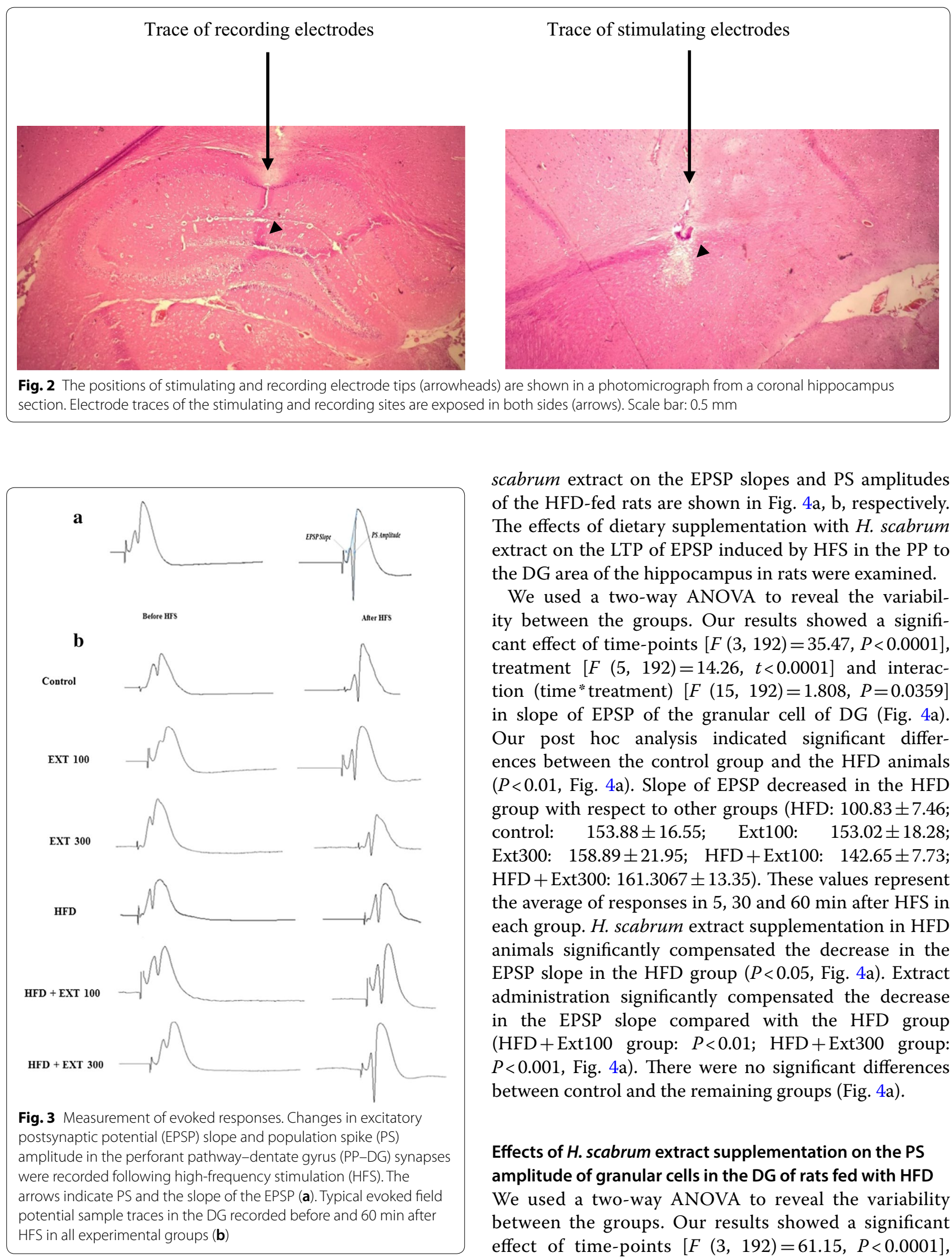

scabrum extract on the EPSP slopes and PS amplitudes of the HFD-fed rats are shown in Fig. 4a, b, respectively. The effects of dietary supplementation with $H$. scabrum extract on the LTP of EPSP induced by HFS in the PP to the DG area of the hippocampus in rats were examined.

We used a two-way ANOVA to reveal the variability between the groups. Our results showed a significant effect of time-points $[F(3,192)=35.47, P<0.0001]$, treatment $[F(5,192)=14.26, t<0.0001]$ and interaction (time*treatment) $[F(15,192)=1.808, P=0.0359]$ in slope of EPSP of the granular cell of DG (Fig. 4a). Our post hoc analysis indicated significant differences between the control group and the HFD animals $(P<0.01$, Fig. 4a). Slope of EPSP decreased in the HFD group with respect to other groups (HFD: $100.83 \pm 7.46$; control: $\quad 153.88 \pm 16.55 ; \quad$ Ext100: $153.02 \pm 18.28$; Ext300: $158.89 \pm 21.95 ; \quad$ HFD + Ext100: $142.65 \pm 7.73$; HFD + Ext300: $161.3067 \pm 13.35)$. These values represent the average of responses in 5, 30 and 60 min after HFS in each group. $H$. scabrum extract supplementation in HFD animals significantly compensated the decrease in the EPSP slope in the HFD group $(P<0.05$, Fig. 4a). Extract administration significantly compensated the decrease in the EPSP slope compared with the HFD group (HFD+Ext100 group: $P<0.01$; HFD + Ext300 group: $P<0.001$, Fig. 4a). There were no significant differences between control and the remaining groups (Fig. 4a).

\section{Effects of $H$. scabrum extract supplementation on the PS amplitude of granular cells in the DG of rats fed with HFD} We used a two-way ANOVA to reveal the variability between the groups. Our results showed a significant effect of time-points $[F(3,192)=61.15, P<0.0001]$, 


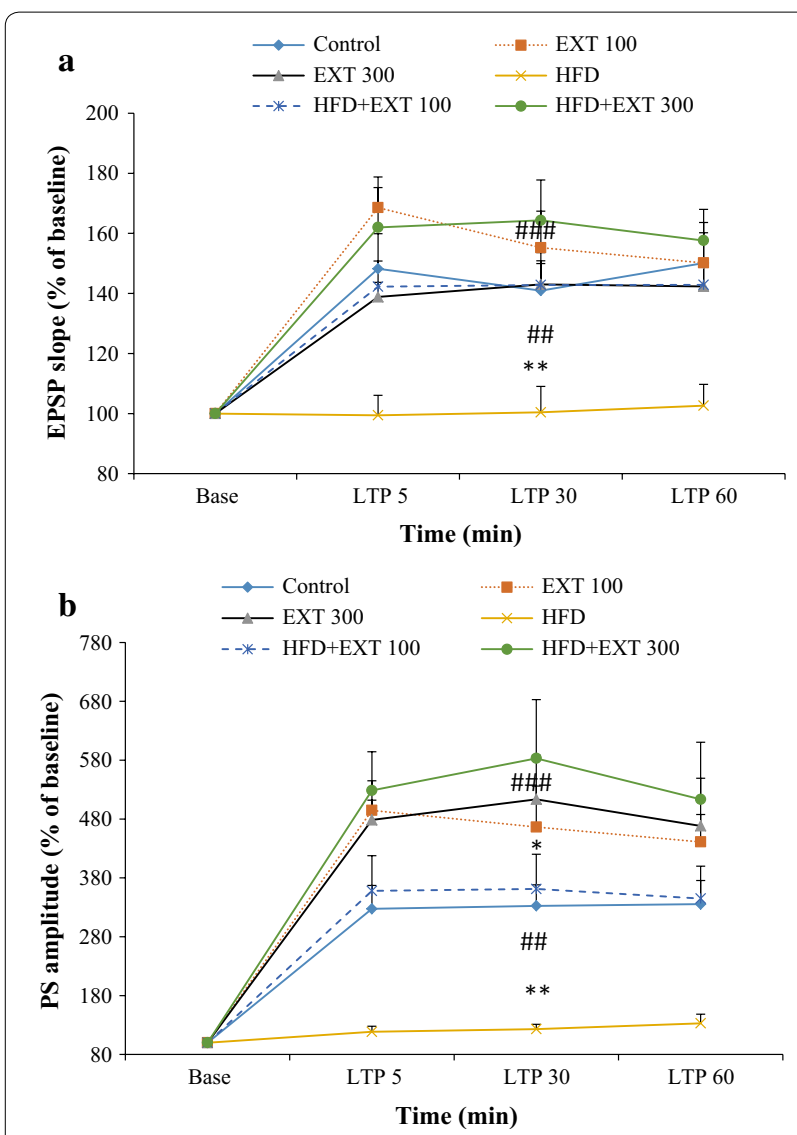

Fig. 4 Time-dependent changes of long-term potentiation (LTP) of the excitatory postsynaptic potentials (EPSP) slope (a) and population spike (PS) (b) amplitudes in dentate gyrus (DG) granular cell synapses in response to perforant pathway (PP) stimulation after a high-frequency stimulation (HFS). Data are shown as means \pm SEM $\%$ of baseline. ${ }^{*} P<0.05$; ${ }^{*} P<0.01$ (compared with control); ${ }^{\# \#} P<0.01$; ${ }^{\# \#} P<0.001$ (compared with HFD)

treatment $[F(5,192)=25.51, P<0.0001]$ and interaction (time * treatment) $[F(15,192)=2.962, P=0.0003]$ in PS amplitude of the granular cell of DG (Fig. 4b). Our post hoc analysis indicated significant differences between the control group and the HFD animals $(P<0.01$, Fig. $4 \mathrm{~b})$. PS amplitude decreased in the HFD group with respect to control group (HFD: 124.88 \pm 11.00 ; control: $331.8 \pm 38.58$; Ext100: 467.45 \pm 71.52 ; Ext300: $459.53 \pm 63.18$; HFD + Ext100: $354.70 \pm 57.95 ; \quad$ HFD + Ext300: $541.73 \pm 87.58) . \quad H$. scabrum extract administration in HFD-fed animals significantly compensated the decrease in the PS amplitude in the $\mathrm{A} \beta$ group $(P<0.001$, Fig. $4 \mathrm{~b})$. In addition, Ext supplementation in control animals enhanced PS amplitude of the granular cell of DG (Fig. 4b). Extract significantly augmented the PS amplitude compared with the HFD group (HFD+Ext100: $P<0.01$;
HFD + Ext300; $P<0.001)$. There were no significant differences between Ext100, Ext300, and control groups (Fig. 4b).

\section{Discussion}

This investigation appraised the effect of the application of the hydroalcoholic extract of $H$. scabrum on synaptic plasticity using the field potential response in HFDtreated rats. The results showed that HFD reduced EPSP slope and PS amplitude in the HFD groups and $H$. scabrum application was able to neutralize the negative effects of HFD on-field potential recordings. Our findings showed that $H$. scabrum extract ameliorates HFDinduced synaptic plasticity deficits, as measured by an augmentation in LTP of granular cells in the DG after stimulation of the PP. It should be noted that only a single LTP was induced in each animal. The induced LTP was compared between experimental groups.

Oxidative stress has been proven to play an essential function in cognitive damage [56]. A balance between free radical production and antioxidant capacity is criti$\mathrm{cal}$, and oxidative stress results from the accumulation of oxidative products [57]. The excess formation of oxidants can cause oxidative stress $[3,58,59]$. A HFD increases plasma-free fatty acids and induces oxidative stress from the accumulation of lipid peroxidation in the hippocampus [60]. It has been reported that oxidative stress causes neurodegenerative diseases such as AD [61]. Mitochondrial injury and HFD-evoked oxidative stress are reasons that could conduce to some forms of neurodegeneration [62]. Furthermore, recent investigations have proposed the use of antioxidant supplementation to decrease oxidative stress-induced neurodegeneration [63, 64]. Some investigations have remarked that oxidative stress causes neural injury in brain regions associated with the etiology of memory damage [65-67]. Furthermore, oxidative stress could influence synaptic plasticity and can lead to diminished LTP induction [40]. In contrast, some of the previous studies have shown that antioxidants improve the induction of hippocampal LTP [68]. An important new finding of this study was that the adverse effects of the HFD were reduced substantially by the administration of the dietary H. scabrum extract. In our study, Ext administration significantly compensated the decrease in the PS amplitude and EPSP slope compared with the HFD group. All of the parts of this plant are sources of fatty acids, especially essential fatty acids, as well as effective natural antioxidants [69]. It has been indicated that, its extract possess flavonoids, such as quercetin [70]; flavonoids act as antioxidants [71]. In confirmation of our results, administration of $H$. scabrum Ext in rats was shown to improve learning and memory and possess antioxidant activity [27]. In accordance with 
this finding, Pintana et al. [72] have shown that an HFD impairs learning and memory, and treatment with garlic extract restores these impairments in obese insulinresistant rats. In our previous investigation [3], the rats in the HFD groups demonstrated a significant reduction in glutathione level in comparison to those in extract and control groups, whereas, the malondialdehyde levels in the HFD groups were significantly greater than those in the extract and control groups. The different investigations discovered that $H$. scabrum protects DNA against oxidative injury via its significant antioxidant effects [73].

HFD-induced obesity and increase in inflammatory markers in animals are connected [74]. Accordingly, a long-term HFD (16 weeks) has been shown to cause anxiety, increase corticosterone level, and increase inflammatory cytokines, such as interleukin- 6 , interleukin- $1 \beta$, and tumor necrosis factor- $\alpha$ [75]. In contrast, H. scabrum extracts have been reported to inhibit both lipoxygenase and cyclooxygenase pathways, which then reduces inflammatory factors [76, 77]. Additionally, it has been reported that, the H. scabrum extract has anti-inflammatory properties [78] that probably result from the flavonoids in the extract [79].

Our investigation indicated that PS amplitude and EPSP slope decreased in the HFD group compared to the control group. Our findings are corroborated by numerous investigations that indicated the negative result of HFD on learning and memory. Consistent with our results, it has been published that HFD can diminish cognitive effects [80] and synaptic plasticity [68]. In accordance with our results, male rats on an HFD exhibit reduced hippocampal neurogenesis [81]. Moreover, HFD compromises the expression of a number of neurotrophic factors that would enhance hippocampal plasticity [2, 82]. Moreover, previous investigations have suggested a link between high-fat intake and cognitive impairment. They found that an HFD reduced hippocampal brainderived neurotrophic factor (BDNF) levels, neuronal plasticity, and learning in rats $[2,83]$. In this line, multiple studies have demonstrated that HFD intake is associated with decreased expression of BDNF in both the hippocampus $[84,85]$ and cortex $[86,87]$ suggesting that the adverse effects of HFD consumption on learning and memory may also be mediated in part by alteration of BDNF-related synaptic plasticity [8].

Hypericum displayed some impacts directly related to brain activity, such as repression of the neuronal reuptake of norepinephrine, 5-HT, L-glutamate, GABA, and DA and augmented receptor binding and neurotransmitter sensitivity [88]. It has been reported that, Hypericum extract has functional impacts, including amelioration of cognitive impairment, neuroprotective effects, and improvement of cognitive performance in rodents [89].

\section{Conclusion}

In conclusion, the current investigation indicates that $H$. scabrum extract treatment can prevent synaptic plasticity impairment caused by HFD. These effects may be a result of the strong anti-inflammatory and antioxidant activity of the extract and its capability to scavenge free radicals. Prospective investigations are required to test further this matter and the precise mechanism underlying the impacts of $H$. scabrum extracts on synaptic plasticity.

\section{Acknowledgements}

This study was supported by a grant (Grant Number: 94011852) of the Hamadan University of Medical Sciences, Hamadan, Iran.

\section{Authors' contributions \\ All authors have assumed responsibility for data integrity and accuracy of the data analysis. Study concept and design: FE, AK. Data acquisition: GO, ARK. Data analysis and interpretation: AG, AK, SK. Drafting of the manuscript: AK, MA. Critical revision of the manuscript for important intellectual content: AK and FE. Statistical analysis: SK, GO, ARK. Study supervision: AK, MA. All authors read and approved the final manuscript.}

\section{Ethics approval and consent to participate}

All animal experimental procedures were performed in accordance with the guidelines for proper conduct of animal experiments issued by the Ethics Committee of the Hamadan University of Medical Sciences, and performed according to the 'Guide for the Care and Use of Laboratory Animals', prepared by the National Academy of Sciences and published by the National Institutes of Health (NIH publication 86-23 revised 1985).

\section{Competing interests}

There is no conflict of interest in this study.

\section{Author details}

${ }^{1}$ Neurophysiology Research Center, Hamadan University of Medical Sciences, Hamadan, Iran. ${ }^{2}$ Rahe Sabz Addiction Rehabilitation Clinic, Hamadan University of Medical Sciences, Hamadan, Iran. ${ }^{3}$ Department of Physiology, School of Medicine, Hamadan University of Medical Sciences, Shahid Fahmideh Street, 65178/518 Hamadan, Iran.

Received: 08 April 2019 Accepted: 09 March 2020

Published online: 24 March 2020

\section{References}

1. WHO J, Consultation FE (2003) Diet, nutrition and the prevention of chronic diseases

2. Molteni R, Barnard R, Ying Z, Roberts C, Gomez-Pinilla F (2002) A high-fat, refined sugar diet reduces hippocampal brain-derived neurotrophic factor, neuronal plasticity, and learning. Neuroscience 112:803-814

3. Ganji A, Salehi I, Sarihi A, Shahidi S, Komaki A (2017) Effects of Hypericum scabrum extract on anxiety and oxidative stress biomarkers in rats fed a long-term high-fat diet. Metab Brain Dis 32:503-511

4. Kesh S, Sarkar D, Manna K (2016) High-fat diet-induced oxidative stress and its impact on metabolic syndrome: a review. Asian J Pharm Clin Res 9:47-52

5. Kim HG, Jeong HU, Park G, Kim H, Lim Y, Oh MS (2015) Mori folium and Mori fructus mixture attenuates high-fat diet-induced cognitive deficits in mice. Evid Based Complement Altern Med. https://doi. org/10.1155/2015/379418

6. Tomiga Y, Yoshimura S, Ra SG, Takahashi Y, Goto R, Kugimoto I, Uehara Y, Kawanaka K, Higaki Y (2019) Anxiety-like behaviors and hippocampal nNOS in response to diet-induced obesity combined with exercise. J Physiol Sci 69:1-12 
7. Beilharz JE, Maniam J, Morris MJ (2015) Diet-induced cognitive deficits: the role of fat and sugar, potential mechanisms and nutritional interventions. Nutrients 7:6719-6738

8. Cordner ZA, Tamashiro KL (2015) Effects of high-fat diet exposure on learning \& memory. Physiol Behav 152:363-371

9. Spencer SJ, D'Angelo H, Soch A, Watkins LR, Maier SF, Barrientos RM (2017) High-fat diet and aging interact to produce neuroinflammation and impair hippocampal-and amygdalar-dependent memory. Neurobiol Aging 58:88-101

10. Levine RL, Stadtman ER (2001) Oxidative modification of proteins during aging. Exp Gerontol 36:1495-1502

11. Kamata H, Hirata H (1999) Redox regulation of cellular signalling. Cell Signal 11:1-14

12. Charradi K, Elkahoui S, Limam F, Aouani E (2013) High-fat diet induced an oxidative stress in white adipose tissue and disturbed plasma transition metals in rat: prevention by grape seed and skin extract. J Physiol Sci 63:445-455

13. Gainey SJ, Kwakwa KA, Bray JK, Pillote MM, Tir VL, Towers AE, Freund GG (2016) Short-term high-fat diet (HFD) induced anxiety-like behaviors and cognitive impairment are improved with treatment by glyburide. Front Behav Neurosci 10:156

14. Klein C, Jonas W, Iggena D, Empl L, Rivalan M, Wiedmer P, Spranger J, Hellweg R, Winter Y, Steiner B (2016) Exercise prevents high-fat diet-induced impairment of flexible memory expression in the water maze and modulates adult hippocampal neurogenesis in mice. Neurobiol Learn Mem 131:26-35

15. Boitard C, Etchamendy N, Sauvant J, Aubert A, Tronel S, Marighetto A Layé S, Ferreira G (2012) Juvenile, but not adult exposure to high-fat diet impairs relational memory and hippocampal neurogenesis in mice. Hippocampus 22:2095-2100

16. Park HR, Park M, Choi J, Park K-Y, Chung HY, Lee J (2010) A high-fat diet impairs neurogenesis: involvement of lipid peroxidation and brainderived neurotrophic factor. Neurosci Lett 482:235-239

17. Ferreira PS, Spolidorio LC, Manthey JA, Cesar TB (2016) Citrus flavanones prevent systemic inflammation and ameliorate oxidative stress in C57BL/6J mice fed high-fat diet. Food Funct 7:2675-2681

18. Delwing-de Lima D, Ulbricht ASSF, Werlang-Coelho C, Delwing-Dal Magro D, Joaquim VHA, Salamaia EM, de Quevedo SR, Desordi L (2018) Effects of two aerobic exercise training protocols on parameters of oxidative stress in the blood and liver of obese rats. J Physiol Sci 68:699-706

19. Gao Y, Ottaway N, Schriever SC, Legutko B, García-Cáceres C, de la Fuente E, Mergen C, Bour S, Thaler JP, Seeley RJ (2014) Hormones and diet, but not body weight, control hypothalamic microglial activity. Glia 62:17-25

20. Spielman LJ, Little JP, Klegeris A (2014) Inflammation and insulin/IGF-1 resistance as the possible link between obesity and neurodegeneration. J Neuroimmunol 273:8-21

21. Sánchez-Sarasúa S, Moustafa S, García-Avilés Á, López-Climent MF, Gómez-Cadenas A, Olucha-Bordonau FE, Sánchez-Pérez AM (2016) The effect of abscisic acid chronic treatment on neuroinflammatory markers and memory in a rat model of high-fat diet induced neuroinflammation. Nutr Metab 13:73

22. Bouayed J, Rammal H, Soulimani R (2009) Oxidative stress and anxiety: relationship and cellular pathways. Oxid Med Cell Longev 2:63-67

23. De Lima MNM, Polydoro M, Laranja DC, Bonatto F, Bromberg E, Moreira JCF, Dal-Pizzol F, Schröder N (2005) Recognition memory impairment and brain oxidative stress induced by postnatal iron administration. Eur J Neurosci 21:2521-2528

24. Del Rosario AR (2012) Impact of obesity on the brain and dietary intervention with bamboo extract. University of Hawaii at Manoa, Honolulu

25. Abe K, Saito H (2000) Effects of saffron extract and its constituent crocin on learning behaviour and long-term potentiation. Phytother Res 14:149-152

26. Esfandiary E, Karimipour M, Mardani M, Ghanadian M, Alaei HA, Mohammadnejad D, Esmaeili A (2015) Neuroprotective effects of Rosa damascena extract on learning and memory in a rat model of amyloid- $\beta$-induced Alzheimer's disease. Adv Biomed Res. https://doi. org/10.4103/2277-9175.161512

27. Ganji A, Salehi I, Nazari M, Taheri M, Komaki A (2017) Effects of Hypericum scabrum extract on learning and memory and oxidant/antioxidant status in rats fed a long-term high-fat diet. Metab Brain Dis 32:1255-1265
28. Rezvani-Kamran A, Salehi I, Shahidi S, Zarei M, Moradkhani S, Komaki A (2017) Effects of the hydroalcoholic extract of Rosa damascena on learning and memory in male rats consuming a high-fat diet. Pharm Biol 55:2065-2073

29. Komaki A, Hoseini F, Shahidi S, Baharlouei N (2016) Study of the effect of extract of Thymus vulgaris on anxiety in male rats. J Tradit Complement Med 6:257-261

30. Jivad N, Rabiei Z (2014) A review study on medicinal plants used in the treatment of learning and memory impairments. Asian Pac JTrop Biomed 4:780-789

31. Ghasemi Pirbalouti A, Fatahi-Vanani M, Craker L, Shirmardi H (2014) Chemical composition and bioactivity of essential oils of Hypericum helianthemoides. Hypericum perforatum and Hypericum scabrum. Pharm Biol 52:175-181

32. Moghadam SE, Moridi Farimani M, Soroury S, Ebrahimi SN, Jabbarzadeh E (2019) Hypermongone $\mathrm{C}$ accelerates wound sealing through the modulation of inflammatory factors and promotion of fibroblast migration. Molecules 24:2022

33. Kennedy DO, Wightman EL (2011) Herbal extracts and phytochemicals: plant secondary metabolites and the enhancement of human brain function. Adv Nutr 2:32-50

34. Eslami B, Nabavi S, Nabavi S, Ebrahimzadeh M, Mahmoudi M (2011) Pharmacological activities of Hypericum scabrum L. Eur Rev Med Pharmacol Sci 15:532-537

35. Mohammed Sur T, Akbaba E, Hassan SA, Bagci E (2019) Neuropharmacological profile of Hypericum scabrum L. essential oil in rats. J Essent Oil Res 32:1-9

36. Dresler S, Kováčik J, Strzemski M, Sowa I, Wójciak-Kosior M (2018) Methodological aspects of biologically active compounds quantification in the genus Hypericum. J Pharm Biomed Anal 155:82-90

37. Zou Y, Lu Y, Wei D (2004) Antioxidant activity of a flavonoid-rich extract of Hypericum perforatum L. in vitro. J Agric Food Chem 52:5032-5039

38. Lee GY, Lee C, Park GH, Jang JH (2017) Amelioration of scopolamineinduced learning and memory impairment by a-pinene in C57BL/6 mice. Evid Based Complement Altern Med. https://doi.org/10.1155/2017/49268 15

39. Keskin C (2015) Antioxidant, anticancer and anticholinesterase activities of flower, fruit and seed extracts of Hypericum amblysepalum HOCHST. Asian Pac J Cancer Prevent 16:2763-2769

40. Komaki H, Faraji N, Komaki A, Shahidi S, Etaee F, Raoufi S, Mirzaei F (2019) Investigation of protective effects of coenzyme Q10 on impaired synaptic plasticity in a male rat model of Alzheimer's disease. Brain Res Bull 147:14-21

41. Blaise JH, Ruskin DN, Koranda JL, Masino SA (2015) Effects of a ketogenic diet on hippocampal plasticity in freely moving juvenile rats. Physiol Rep 3:e12411

42. Jedlicka P, Hoon M, Papadopoulos T, Vlachos A, Winkels R, Poulopoulos A, Betz H, Deller T, Brose N, Varoqueaux F (2010) Increased dentate gyrus excitability in neuroligin-2-deficient mice in vivo. Cereb Cortex 21:357-367

43. Blaise J, Arnett A (2006) Effects of LTP induction on hippocampal cellular excitability in the freely behaving developing rat brain. In: 2006 international conference of the IEEE engineering in medicine and biology society. IEEE, New York, pp 4965-4966

44. Nakashiba T, Cushman JD, Pelkey KA, Renaudineau S, Buhl DL, McHugh TJ, Barrera VR, Chittajallu R, Iwamoto KS, McBain CJ (2012) Young dentate granule cells mediate pattern separation, whereas old granule cells facilitate pattern completion. Cell 149:188-201

45. Andersen P, Bliss TV, Skrede K (1971) Unit analysis of hippocampal population spikes. Exp Brain Res 13:208-221

46. Jedlicka P, Vnencak M, Krueger DD, Jungenitz T, Brose N, Schwarzacher SW (2015) Neuroligin-1 regulates excitatory synaptic transmission, LTP and EPSP-spike coupling in the dentate gyrus in vivo. Brain Struct Funct 220:47-58

47. Moradkhani S, Salehi I, Abdolmaleki S, Komaki A (2015) Effect of Calendula officinalis hydroalcoholic extract on passive avoidance learning and memory in streptozotocin-induced diabetic rats. Anc Sci Life 34:156

48. Komaki H, Saadat F, Shahidi S, Sarihi A, Hasanein P, Komaki A (2017) The interactive role of $\mathrm{CB} 1$ receptors and L-type calcium channels in hippocampal long-term potentiation in rats. Brain Res Bull 131:168-175 
49. Nazari M, Komaki A, Salehi I, Sarihi A, Shahidi S, Komaki H, Ganji A (2016) Interactive effects of AM251 and baclofen on synaptic plasticity in the rat dentate gyrus. Brain Res 1651:53-60

50. Paxinos G, Watson C (2005) The rat brain in stereotaxic coordinates. Elsevier Academic Press, San Diego

51. Nazari M, Komaki A, Karamian R, Shahidi S, Sarihi A, Asadbegi M (2016) The interactive role of CB 1 and GABA B receptors in hippocampal synaptic plasticity in rats. Brain Res Bull 120:123-130

52. Asadbegi M, Yaghmaei P, Salehi I, Ebrahim-Habibi A, Komaki A (2016) Neuroprotective effects of metformin against $A \beta$-mediated inhibition of long-term potentiation in rats fed a high-fat diet. Brain Res Bull 121:178-185

53. Tahmasebi L, Komaki A, Karamian R, Shahidi S, Sarihi A, Komaki H (2016) Interaction between paired-pulse facilitation and long-term potentiation during the stimulation of the cannabinoid and vanilloid systems in the dentate gyrus. Brain Res 1643:27-34

54. Taube J, Schwartzkroin P (1988) Mechanisms of long-term potentiation: EPSP/spike dissociation, intradendritic recordings, and glutamate sensitivity. J Neurosci 8:1632-1644

55. Komaki A, Shahidi S, Lashgari R, Haghparast A, Malakouti SM, Noorbakhsh SM (2007) Effects of GABAergic inhibition on neocortical long-term potentiation in the chronically prepared rat. Neurosci Lett 422:181-186

56. Alzoubi KH, Khabour OF, Salah HA, Hasan Z (2013) Vitamin E prevents high-fat high-carbohydrates diet-induced memory impairment: the role of oxidative stress. Physiol Behav 119:72-78

57. Lozano I, Van der Werf R, Bietiger W, Seyfritz E, Peronet C, Pinget M, Jeandidier N, Maillard E, Marchioni E, Sigrist S (2016) High-fructose and high-fat diet-induced disorders in rats: impact on diabetes risk, hepatic and vascular complications. Nutr Metab 13:15

58. Di Pasqua R, Mamone G, Ferranti P, Ercolini D, Mauriello G (2010) Changes in the proteome of Salmonella enterica serovar Thompson as stress adaptation to sublethal concentrations of thymol. Proteomics 10:1040-1049

59. Wang S-Q, Li D, Yuan Y (2019) Long-term moderate intensity exercise alleviates myocardial fibrosis in type 2 diabetic rats via inhibitions of oxidative stress and TGF- $\beta 1 /$ Smad pathway. J Physiol Sci 69:1-13

60. Yamato M, Shiba T, Yoshida M, Ide T, Seri N, Kudou W, Kinugawa S, Tsutsui $H$ (2007) Fatty acids increase the circulating levels of oxidative stress factors in mice with diet-induced obesity via redox changes of albumin. FEBS J 274:3855-3863

61. Rosini M, Simoni E, Milelli A, Minarini A, Melchiorre C (2013) Oxidative stress in Alzheimer's disease: are we connecting the dots? Miniperspective. J Med Chem 57:2821-2831

62. Nuzzo D, Picone P, Baldassano S, Caruana L, Messina E, Marino Gammazza A, Cappello F, Mule F, Di Carlo M (2015) Insulin resistance as common molecular denominator linking obesity to Alzheimer's disease. Curr Alzheimer Res 12:723-735

63. Kızıl G, Kızıl M, Yavuz M, Emen S, Hakimoğlu F (2008) Antioxidant activities of ethanol extracts of Hypericum triquetrifolium and Hypericum scabroides. Pharm Biol 46:231-242

64. Pourkhodadad S, Alirezaei M, Moghaddasi M, Ahmadvand H, Karami M, Delfan B, Khanipour Z (2016) Neuroprotective effects of oleuropein against cognitive dysfunction induced by colchicine in hippocampal CA1 area in rats. J Physiol Sci 66:397-405

65. Caceres LG, Bertolino LA, Saraceno GE, Zubilete MAZ, Uran SL, Capani F, Guelman LR (2010) Hippocampal-related memory deficits and histological damage induced by neonatal ionizing radiation exposure. Role of oxidative status. Brain Res 1312:67-78

66. Dumont M, Beal MF (2011) Neuroprotective strategies involving ROS in Alzheimer disease. Free Radic Biol Med 51:1014-1026

67. Alirezaei M, Rezaei M, Hajighahramani S, Sookhtehzari A, Kiani K (2017) Oleuropein attenuates cognitive dysfunction and oxidative stress induced by some anesthetic drugs in the hippocampal area of rats. J Physiol Sci 67:131-139

68. Asadbegi M, Komaki A, Salehi I, Yaghmaei P, Ebrahim-Habibi A, Shahidi S, Sarihi A, Asl SS, Golipoor Z (2018) Effects of thymol on amyloid- $\beta$-induced impairments in hippocampal synaptic plasticity in rats fed a high-fat diet. Brain Res Bull 137:338-350

69. Shafaghat A (2011) Antioxidant, antimicrobial activities and fatty acid components of flower, leaf, stem and seed of Hypericum scabrum. Nat Product Commun 6:1934578X1100601142
70. Jiang L, Numonov S, Bobakulov K, Qureshi MN, Zhao H, Aisa HA (2015) Phytochemical profiling and evaluation of pharmacological activities of Hypericum scabrum L. Molecules 20:11257-11271

71. Cook N, Samman S (1996) Flavonoids_chemistry, metabolism, cardioprotective effects, and dietary sources. J Nutr Biochem 7:66-76

72. Pintana H, Sripetchwandee J, Supakul L, Apaijai N, Chattipakorn N, Chattipakorn S (2014) Garlic extract attenuates brain mitochondrial dysfunction and cognitive deficit in obese-insulin resistant rats. Appl Physiol Nutr Metab 39:1373-1379

73. Kızıl G, Kızıl M, Çeken B, Yavuz M, Demir H (2011) Protective ability of ethanol extracts of Hypericum scabrum L. and Hypericum retusum Aucher against the protein oxidation and DNA damage. Int J Food Prop 14:926-940

74. Moya-Pérez A, Neef A, Sanz Y (2015) Bifidobacterium pseudocatenulatum CECT 7765 reduces obesity-associated inflammation by restoring the lymphocyte-macrophage balance and gut microbiota structure in highfat diet-fed mice. PLOS ONE 10:e0126976

75. Dutheil S, Ota KT, Wohleb ES, Rasmussen K, Duman RS (2016) High-fat diet induced anxiety and anhedonia: impact on brain homeostasis and inflammation. Neuropsychopharmacology 41:1874

76. Kim H, Mani I, Iversen L, Ziboh V (1998) Effects of naturally-occurring flavonoids and biflavonoids on epidermal cyclooxygenase and lipoxygenase from guinea-pigs. Prostaglandins Leukot Essen Fatty Acids 58:17-24

77. Nijveldt RJ, Van Nood E, Van Hoorn DE, Boelens PG, Van Norren K, Van Leeuwen PA (2001) Flavonoids: a review of probable mechanisms of action and potential applications. Am J Clin Nutr 74:418-425

78. Hamzeloo-Moghadam M, Khalaj A, Malekmohammadi M (2015) Cytotoxic activity and apoptosis induction of Hypericum scabrum L. Iran Red Crescent Med J 17:e19453

79. Vauzour D, Vafeiadou K, Rodriguez-Mateos A, Rendeiro C, Spencer JP (2008) The neuroprotective potential of flavonoids: a multiplicity of effects. Genes Nutr 3:115

80. Asadbegi M, Yaghmaei P, Salehi I, Komaki A, Ebrahim-Habibi A (2017) Investigation of thymol effect on learning and memory impairment induced by intrahippocampal injection of amyloid beta peptide in high fat diet-fed rats. Metab Brain Dis 32:827-839

81. Lindqvist A, Mohapel P, Bouter B, Frielingsdorf H, Pizzo D, Brundin P, Erlanson-Albertsson C (2006) High-fat diet impairs hippocampal neurogenesis in male rats. Eur J Neurol 13:1385-1388

82. Stranahan AM, Norman ED, Lee K, Cutler RG, Telljohann RS, Egan JM, Mattson MP (2008) Diet-induced insulin resistance impairs hippocampal synaptic plasticity and cognition in middle-aged rats. Hippocampus 18:1085-1088

83. Zhang X, Dong F, Ren J, Driscoll MJ, Culver B (2005) High dietary fat induces NADPH oxidase-associated oxidative stress and inflammation in rat cerebral cortex. Exp Neurol 191:318-325

84. Kishi T, Hirooka Y, Nagayama T, Isegawa K, Katsuki M, Takesue K, Sunagawa K (2014) Calorie restriction improves cognitive decline via up-regulation of brain-derived neurotrophic factor. Int Heart J 56:14-168

85. Kanoski SE, Meisel RL, Mullins AJ, Davidson TL (2007) The effects of energy-rich diets on discrimination reversal learning and on BDNF in the hippocampus and prefrontal cortex of the rat. Behav Brain Res 182:57-66

86. Kaczmarczyk MM, Machaj AS, Chiu GS, Lawson MA, Gainey SJ, York JM, Meling DD, Martin SA, Kwakwa KA, Newman AF (2013) Methylphenidate prevents high-fat diet (HFD)-induced learning/memory impairment in juvenile mice. Psychoneuroendocrinology 38:1553-1564

87. Camer D, Yu Y, Szabo A, Fernandez F, Dinh CH, Huang X-F (2015) Bardoxolone methyl prevents high-fat diet-induced alterations in prefrontal cortex signalling molecules involved in recognition memory. Prog NeuroPsychopharmacol Biol Psychiatry 59:68-75

88. Butterweck V (2003) Mechanism of action of St John's wort in depression. CNS Drugs 17:539-562

89. Kumar V, Mdzinarishvili A, Kiewert C, Abbruscato T, Bickel U, van der Schyf CJ, Klein J (2006) NMDA receptor-antagonistic properties of hyperforin, a constituent of St John's Wort. J Pharmacol Sci 102:47-54

\section{Publisher's Note}

Springer Nature remains neutral with regard to jurisdictional claims in published maps and institutional affiliations. 